\title{
Development and Validation of a Computerized Assessment Form to Support Nursing Diagnosis
}

\author{
Maurizio Zega, RN, MSN, Fabio D'Agostino, RN, MSN, Kathryn H. Bowles, PhD, RN, FAAN, \\ Maria Grazia De Marinis, RN, MSN, Gennaro Rocco, RN, MSN, Ercole Vellone, RN, MSN, and \\ Rosaria Alvaro, RN, MSN \\ Maurizio Zega, RN, MSN, is a PhD Candidate, Fabio D'Agostino, RN, MSN, is a Research Fellow, School of Nursing, \\ University Tor Vergata, Rome, Italy; Kathryn H. Bowles, PhD, RN, FAAN, is a Professor, School of Nursing, University of \\ Pennsylvania, Philadelphia; Maria Grazia De Marinis, RN, MSN, is an Associate Professor, School of Nursing, University \\ Campus Bio Medico; Gennaro Rocco, RN, MSN, is President, Center of Excellence for Nursing Scholarship; Ercole Vellone, \\ RN, MSN, is a Research Fellow, and Rosaria Alvaro, RN, MSN, is an Associate Professor, School of Nursing, University Tor \\ Vergata, Rome, Italy
}

\section{Search terms: \\ Computer-assisted, decision \\ support, diagnosis, nursing \\ assessment, nursing diagnosis}

\section{Author contact:}

dagostinofabi@hotmail.it, with a

copy to the Editor:

journal@nanda.org

Conflicts of interest and source of

funding: The authors have no conflicts of interest to disclose. This study was funded by the Center of Excellence for Nursing Scholarship, Rome, Italy.
PURPOSE: Describe the development and validation of the Nursing Assessment Form (NAF), within a clinical nursing information system, to support nurses in the identification of nursing diagnoses.

METHODS: Content validity and consensus on NAF contents were established using a panel of experts in nursing diagnosis and Delphi rounds.

FINDINGS: Expert consensus was achieved to validate an instrument to support nurses in the process of nursing diagnoses identification.

CONCLUSIONS: The use of the NAF can help nurses in diagnostic reasoning, facilitating the identification of the more suitable nursing diagnoses, and provide a basis for the best nursing interventions and outcomes.

IMPLICATIONS FOR NURSING PRACTICE: The use of computerized decision support can improve the implementation of standardized terminology and the accuracy of nursing diagnosis.

SCOPO: Descrivere lo sviluppo e il processo di validazione della Scheda di Accertamento Infermieristico (SAI), contenuta all'interno di un sistema informativo infermieristico, ideata al fine di supportare gli infermieri nel processo di identificazione delle diagnosi infermieristiche.

METODI: La validità di contenuto e il consenso sui contenuti della SAI sono state stabilite tramite un panel di esperti sulla diagnosi infermieristica e Delphi rounds. RISULTATI: Un consenso di esperti è stato ottenuto al fine di validare uno strumento utile per supportare gli infermieri nel processo di identificazione delle diagnosi infermieristiche.

CONCLUSIONI: L'Uso della SAI può aiutare gli infermieri nel ragionamento diagnostico, facilitando l'identificazione delle diagnosi infermieristiche più adatte e fornire una base per i migliori interventi e risultati infermieristici.

IMPLICAZIONI PER LA PRATICA INFERMIERISTICA: L'uso di sistemi di supporto decisionale computerizzati può favorire l'implementazione della terminologia standard e l'accuratezza della diagnosi infermieristica.
In clinical practice, the correct identification of nursing diagnosis is essential to properly plan care, to make appropriate interventions, and to evaluate the nursing care delivered (Carpenito-Moyet, 2008; Johnson, Bulechek, McCloskey Dochterman, Maas, \& Moorhead, 2001). Welton and Halloran (2005) demonstrated improved predictive power ranging from $30 \%$ to $146 \%$ when using nursing diagnoses as the independent variable, versus using diagnosisrelated groups alone, for the outcomes of length of stay, overall healthcare costs, and hospital mortality rate.
Nevertheless, analysis of clinical documentation shows that nurses have difficulties formulating nursing diagnoses, and several international studies show that nursing diagnosis are seldom reported (Bergh, Bergh, \& Friberg, 2007; De Marinis et al., 2010; Häyrinen, Lammintakanen, \& Saranto, 2010). Studies suggest nursing deficits in making accurate nursing diagnosis due to inadequate reporting of defining characteristics (signs/symptoms) and etiological factors (Müller-Staub, Lavin, Needham, \& van Achterberg, 2006; Müller-Staub, Needham, Odenbreit, Lavin, \& van 
Achterberg, 2007; Paans, Sermeus, Nieweg, \& van der Schans, 2010; Thoroddsen \& Ehnfors, 2007). In clinical practice, the prevalence and accuracy of nursing diagnoses documentation are influenced by several factors, such as nurse as a diagnostician, diagnostic education and resources, complexity of a patient's situation, and hospital policy and environment (Paans, Nieweg, van der Schans, \& Sermeus, 2011). The use of specific tools designed to assist nurses and other health professionals to identify nursing diagnoses can improve the efficiency (Kurashima, Kobayashi, Toyabe, \& Akazawa, 2008) and accuracy of the diagnostic process (Lemay, Cashman, Savageau, \& Reidy, 2004). Using a computerized system that generates care plans (Higuchi, Dulberg, \& Duff, 1999) or that links the identified signs and symptoms to the diagnosis may support the use of nursing diagnosis in clinical practice (Paganin, Moraes, Pokorski, \& Rabelo, 2008).

\section{Background}

The accuracy and efficiency of nursing diagnoses rely primarily on the accurate identification of signs and symptoms associated with the possible diagnosis (MüllerStaub, Needham, Odenbreit, Lavin, \& van Achterberg, 2008). The nursing assessment is the first step of the nursing process and represents the basis for identifying the signs and symptoms that support nursing diagnoses (Gordon, 1994; Lunney, 2010). As it is the first stage of the nursing process, any error or omission made during the nursing assessment may affect all of the subsequent steps of the process. The American Nurses Association standards for competent nursing practice include the assessment and definition of nursing diagnosis (American Nurses Association, 2010).

The Italian health policies in force concerning both the nursing profession and the data of nursing interest (Agency for Public Health, Lazio Region Directive No. 6, 2010; Law Decree No. 251, 2000; Ministerial Decree No. 739, 1994) steer nurses toward planned care, with the purpose of identifying clients' care needs and developing a nursing care plan.

The nursing assessment provides useful data for formulating the nursing diagnoses, leading to a care plan of appropriate interventions. The data can be of multiple types, such as biological, psychological, social, and spiritual. They are collected objectively through physical examination of the client, or subjectively from client self-report. Although in clinical practice structured nursing assessment forms, based on a nursing model, are frequently used, the collected data are not often translated into nursing diagnosis. Paans and colleagues (2010) pointed out that although the nursing assessments as a whole were accurate, the documentation of nursing diagnoses was inadequate and incoherent. Further, the nursing documentation was chronological and descriptive rather than focused on clients' problems. To develop a nursing diagnosis, the nurse must possess intellectual, interpersonal, and technical abili- ties (Lunney, 2010). Several authors argue that the use of an assessment form with links to nursing diagnosis may facilitate diagnostic reasoning (Bernhart-Just, Lassen, \& Schwendimann, 2010; Kurashima et al., 2008).

The aim of this study was to develop a computerized nursing assessment form to facilitate the diagnostic reasoning of nurses to identify nursing diagnoses and then estimate its content validity. The distinctive feature of this form lies in the fact that it makes available suggestions of possible nursing diagnoses by linking items (signs/ symptoms and risk factors) on the form itself with particular nursing diagnoses. This assessment form is part of a clinical nursing information system, called Professional Assessment Instrument (PAI), yet to be tested in a clinical setting (D'Agostino, Vellone, Tontini, Zega, \& Alvaro, 2012).

\section{Previous Nursing Assessment Forms}

The researchers searched the Cumulative Index to Nursing and Allied Health Literature and MEDLINE databases from 1985 to 2010 to identify the existence of validated nursing assessment forms specifically designed to provide support in the identification of nursing diagnoses. Papers written in English or Italian were included. The key words used for the search, both individually and in combination, were "nursing," "nursing assessment," "assessment form," "assessment instrument," "clinical decision support," and "diagnosis, computer-assisted." Titles and abstracts of all identified papers were carefully evaluated for their relevance to the subject.

The research yielded four papers:

- The Nursing Process Electronic Documentation System of the University of Sao Paulo (USP-PROCEnf) is an electronic nursing documentation system that allows documentation of nursing process using a standardized terminology (Peres et al., 2010). Only after the nurse has answered a set of branched questionnaires does the USPPROCEnf generate a list of possible diagnoses. The branched questionnaires are based on definitions, defining characteristics, and related factors or risk factors of each diagnosis. The linkages between answers to the questionnaires and possible diagnoses were defined by consensus of a Nursing Research Group. The criteria followed by the Nursing Research Group to specify the trigger answers to identify the nursing diagnoses are not shown in detail.

- The Electronic Nursing Process Data Model (ENPDM) is an electronic nursing documentation system that uses a standardized nursing language, the NANDA, NIC, NOC (NNN) terminologies, for the integration of the nursing process into a clinical information system (Bernhart-Just et al., 2010). The ENPDM provides a focused assessment tool made of questions, specific instruments, or scales that allow collected data to be assigned to the appropriate item to formulate nursing diagnoses. It is unclear whether the assessment provides support to nurses in identifying 
the diagnosis; in addition, the characteristics of validity of the assessment and criteria to identify the items included in the assessment are not mentioned in this study.

- The Nursing Process Support System in Chinese (NPSSC) is a computerized system that allows documentation of nursing care in the nursing home (Yeh et al., 2009). After entering some data in the health assessment, the NPSCC automatically triggers the appropriate nursing diagnoses. Some validated measurement scales are provided to assess care needs. However, in general, there is no evidence about the validity or accuracy of the NPSCC to identify diagnoses or information about the criteria chosen that triggers the identification of the appropriate nursing diagnosis.

- The computer-aided nursing (CAN) diagnosis system is a hospital information system that uses nursing diagnosis (Kurashima et al., 2008). Once the cues are identified, the CAN suggests the nursing diagnoses. The effectiveness and efficiency of CAN have been tested using simulated case studies. The use of CAN improves the efficiency of the diagnostic process, reducing time required for diagnosis, but the effect of CAN on accuracy of nursing diagnoses is not clear. The chosen criteria for the identification of the trigger cues used to identify the nursing diagnoses are not shown.

In all the nursing assessment forms described above, there is a link between cues collected during assessment and nursing diagnoses, and all the forms suggest hypotheses of nursing diagnoses that nurses must confirm. The ENPDM and the NPSSC also use specific scales to collect data during assessment and link these data to nursing diagnoses. Nursing diagnoses in all the electronic systems are based on the NANDA-I taxonomy. All the nursing assessment forms are developed for a hospital setting, except the NPSSC which is developed for a nursing home. In all the existing electronic systems, a limited list of NANDA-I nursing diagnoses is available.

None of the aforementioned studies had clearly declared the validity of the nursing assessment forms specifically designed to provide support in the identification of nursing diagnoses. Therefore, we decided to develop and estimate the validity of a semi-structured nursing assessment form (NAF).

\section{Methods}

\section{Development of the NAF}

This study was carried out in two steps: first, NAF was developed by identifying structure, contents, and links; second, NAF was validated by the domain experts.

\section{Step 1: Development of the NAF}

A research team composed of four expert nurses began to develop the NAF, a semi-structured nursing assessment form. The form was also designed to make it possible to enter additional recordings in free text. The structure of the NAF is based on Gordon's functional health patterns (Gordon, 1994). The functional health patterns were chosen because they can be used in any nursing care setting, they are holistic (bio-psycho-social-spiritual sphere), and they are the basis of the nursing diagnoses in the NANDA-I taxonomy (Herdman, 2012). The contents of the NAF include the defining characteristics and risk factors associated with the nursing diagnoses. These defining characteristics and risk factors were included within the various Gordon's functional health patterns as structured items. The purpose of the NAF is to provide, once completed, suggestions on nursing diagnoses to the nurses.

The suggestions are brought about by specific algorithms that create links between assessment findings and diagnoses. As the nurse completes a patient assessment and selects particular signs and symptoms, algorithms are calculated from this input, and output is generated in the form of suggested nursing diagnoses.

First, the research team chose to include the defining characteristics of each actual diagnosis and the risk factors of each risk diagnosis. The defining characteristics are the signs and symptoms, and the risk factors are situations that increase the vulnerability to an unhealthful event, observed by the nurse or reported by the client, and are also indicators to estimate nursing diagnosis accuracy (Gordon, 2008). Then, as the high number of defining characteristics for each actual diagnosis would result in an overly complex $N A F$, it was decided to take into account for each actual diagnosis only its major defining characteristics. The research team chose the major defining characteristics and risk factors reported by NANDA-I (Gordon, 2008). The major defining characteristics are signs/symptoms that necessarily must be present for the diagnosis is validated (Carpenito-Moyet, 2008). Related factors were not included in the NAF because in the diagnostic process for formulating a correct nursing diagnosis nurses first need to collect cues that are signs and symptoms or risk factors (Gordon, 1994). After nurses have interpreted and clustered these cues, the final task in the diagnostic process is to record the diagnosis with its related factors and cues. Indeed, after the nurse selects a diagnosis, the PAI allows nurses to add the related factors from a list based on NANDA-I for each diagnosis (Gordon, 2008). So nurses word the nursing diagnosis using the PES format, where $P$ represents the problem statement, E represents the etiologies or related factors of the problem, and S represents the signs or symptoms of the problem.

\section{Description of the NAF}

The resulting NAF is a structured form with specific items that reflect the signs-symptoms and risk factors of the 44 nursing diagnoses within the PAI. The PAI is an electronic nursing record that allows nurses to document nursing care in clinical settings using a standard nursing language 
(nursing diagnoses, nursing interventions, and nursing outcomes). The PAI was developed to aid the decision-making process by suggesting nursing diagnoses, interventions, and outcomes. The NAF is part of the PAI and represents its assessment form. The selection of the 44 diagnoses is based on the literature review that showed the prevalence of these diagnoses within various care settings, and on the analysis of nursing diagnoses reported in nursing documentation of Italian hospitals (D'Agostino et al., 2012). The diagnosis terms are based on NANDA-I (Gordon, 2008).

The NAF is divided into 11 sections: nine sections reflecting the Gordon's functional health patterns (health perception and management, nutritional metabolic, elimination, activity exercise, sleep rest, cognitive-perceptual, selfperception/self-concept, role relationship, coping-stress tolerance), and three sections regarding the physical examination of the respiratory and cardiovascular functions, of the skin and mucous membrane status, and the presence of invasive devices. Each section of the questionnaire, in addition to the specific-structured items (signs-symptoms and risk factors), has the chance to include data and observations in free text. The input of the data regarding the alteration of the health status, available in each item, allows the PAl to prompt the nurse with some possible diagnoses (Figure 1). These diagnoses are accepted or rejected by the nurse, thereby preserving the decision-making autonomy of the nurse. The use of the NAF is not merely confined to during the admission of the client, but in any other situation in which the nurse believes it is useful to gather further data to document changes that occurred in the client's diagnostic status. The NAF is intended as a standard assessment tool to be used both in acute care and post-acute care settings.

\section{Step 2: Validation of the NAF}

A panel of expert nurses was appointed to review and validate the list of signs/symptoms and risk factors suggested by the research team. The selection criteria to compose the expert panel included a minimum of 5 years of experience in clinical nursing and/or in nursing teaching/ research, with particular emphasis on clinical and theoretical experience with nursing diagnoses. Hence, 11 nurses were included in the panel. Experts (six male and five female) had a mean professional experience of $18 \pm 9.3$ years and a mean age of $40.5 \pm 8.5$ years; their professional expertise ranges widely in the following areas: nursing clinical care $(n=6)$, associate professor $(n=2)$, nursing researcher $(n=1)$, and nursing management $(n=2)$, while their academic expertise varied from Doctor of Philosophy in nursing $(n=1)$, Master of Science in Nursing $(n=7)$, and Post Master's Clinical Nurse Specialist $(n=3)$. Regarding the professional trajectory and main working areas, the experts included in the panel were nursing service managers, nursing researchers, and nurses in medical-surgical, intensive care, cardiology, and oncology units. The experts were provided with detailed information regarding the process and their role, as recommended by Lynn (1986). As a measure of content validity, the experts were requested to examine the items proposed for each diagnosis and to evaluate if the items were relevant to the correct identification of the related diagnosis. For their responses, experts were given a questionnaire with a 4-point ordinal rating scale $(1=$ an irrelevant item, 2 = a somewhat relevant item, 3 = a quite relevant item, and 4 = an extremely relevant item); a part of the questionnaire is shown in Table 1.

Figure 1. An Example on How the Nursing Assessment Form (NAF) Works at the Point of Care Notes: Data collected with the NAF, by tablet or portable computer, generate nursing diagnoses. For example, selecting "totally dependent" or "partially dependent" from the drop-down menu of the item "independence in dressing/undressing," the system generates the nursing diagnosis "dressing self-care deficit." Then, nurses must confirm the diagnosis. a Nursing Diagnoses-Definitions and Classification 2012-2014. Copyright (c) 2012, 1994-2012 by NANDA-I. Used by arrangement with John Wiley \& Sons Limited. In order to make safe and effective judgments using NANDA-I nursing diagnoses, it is essential that nurses refer to the definitions and defining characteristics of the diagnoses listed in this work.

$\left.\begin{array}{|l}\hline \text { Selected NAF items } \\ \checkmark \text { Independence in dressing/undressing: TOTALLY DEPENDENT } \\ \text { or } \\ \checkmark \text { Independence in dressing/undressing: PARTLY DEPENDENT }\end{array}\right] \longrightarrow$ Dressing self-care deficit ${ }^{\mathrm{a}}$


Table 1. A Part of the Questionnaire Used for the Content Validity of the Nursing Assessment Form: We ask you to
evaluate the relevance of each item to the correct identification of the related nursing diagnosis and make any comment you feel is necessary to improve the assessment form

\begin{tabular}{|c|c|c|c|c|c|}
\hline Nursing Diagnosis & Item & Irrelevant & $\begin{array}{l}\text { Somewhat } \\
\text { relevant }\end{array}$ & $\begin{array}{l}\text { Quite } \\
\text { relevant }\end{array}$ & $\begin{array}{l}\text { Extremely } \\
\text { relevant }\end{array}$ \\
\hline \multirow[t]{3}{*}{ Constipation $^{a}$} & $\begin{array}{l}\text { Frequency of bowel evacuations (weekly): } \\
<2 \text { TIMES }\end{array}$ & 1 & 2 & 3 & 4 \\
\hline & $\begin{array}{l}\text { Reduced frequency of bowel evacuation over the } \\
\text { last } 3 \text { months: YES }\end{array}$ & 1 & 2 & 3 & 4 \\
\hline & Consistency of stool: HARD & 1 & 2 & 3 & 4 \\
\hline & Frequency of bowel evacuations (daily) > 3: YES & 1 & 2 & 3 & 4 \\
\hline Additional comments? & & & & & \\
\hline \multirow[t]{2}{*}{ Dressing self-care deficit ${ }^{a}$} & $\begin{array}{l}\text { Independence in dressing/undressing: PARTLY } \\
\text { DEPENDENT }\end{array}$ & 1 & 2 & 3 & 4 \\
\hline & $\begin{array}{l}\text { Independence in dressing/undressing: TOTALLY } \\
\text { DEPENDENT }\end{array}$ & 1 & 2 & 3 & 4 \\
\hline
\end{tabular}

aNursing Diagnoses-Definitions and Classification 2012-2014. Copyright @ 2012, 1994-2012 by NANDA-I. Used by arrangement with John Wiley \& Sons Limited. In order to make safe and effective judgments using NANDA-I nursing diagnoses, it is essential that nurses refer to the definitions and defining characteristics of the diagnoses listed in this work.

For each one of the 44 nursing diagnoses within the PAI, the experts examined the related items of every single diagnosis. All the experts' answers were received within 1 month after dispatch. Then, the research team calculated the content validity for each item and each diagnosis, and combined the comments providing adequate evidence to refine and change the NAF and the links between the NAF and diagnosis.

Data were collected using structured questionnaires from January 2011 to April 2011, after obtaining the experts' consent to participate. The questionnaires were sent by electronic mail. Content validity index for items (I-CVI) and for diagnoses (D-CVI/Ave) was established. The I-CVI was calculated as the number of experts who gave a rating of 3 or 4 divided by the total number of experts (e.g., an item that was rated as quite relevant or extremely relevant by nine of the eleven experts has received an I-CVI of 0.82). The D-CVI/Ave for each diagnosis was calculated, summing the I-CVI of each item related to the specific nursing diagnosis and dividing that number by the total number of items for that diagnosis. Adequate agreement was established based on procedures outlined by Lynn (1986). Signs and symptoms or risk factors with experts' consensus of $78 \%$ or higher, and diagnoses with experts' consensus of $90 \%$ or higher, were considered valid. Free comments in the questionnaire allowed experts to provide further information useful to improve the NAF.

Content validity was assessed through the application of the Delphi technique. This technique aims to reach a consensus among experts' opinions on a topic through a series of structured questionnaires, called phases (Hasson, Keeney, \& McKenna, 2000). The experts indicated their opinion on the inclusion and exclusion of each item of the
NAF, and suggested revisions. Answers to each questionnaire are taken into account to formulate subsequent ones. Thus, each phase is constructed on the responses from the previous phase, and the process continues until agreement is reached among experts (consensus). The criteria for sending questionnaire back for phase 2 of Delphi were experts' comments and a D-CVI/Ave less than $90 \%$. The items that did not attain a degree of agreement of at least $78 \%$, through group discussions of the research team, were excluded from linking with the nursing diagnosis. The Delphi technique was applied in two phases to reach a consensus.

\section{Results}

\section{NAF Content Validity Delphi Phase 1}

Answers to the first questionnaire showed an excellent I-CVI for most items with a high degree of agreement, above $80 \%$. Table 2 illustrates I-CVI of two nursing diagnoses. The D-CVI/Ave for 37 of the 44 diagnosis was equal to or greater than 90\%, as shown in Table 3. Three diagnoses reached consensus in the $\mathrm{D}-\mathrm{CVI}$, but some items did not achieve an adequate CVI. Seven diagnoses did not reach consensus in the D-CVI, and the related items needed to be redrafted. Seven diagnoses shared the same items (signs/ symptoms), which did not achieve an adequate I-CVI (less than $78 \%$ ). The experts pointed out that a reformulation of these items was needed. In particular, the items identifying an altered mental status were estimated by the experts as too general and not related to the diagnosis; in addition, the panel proposed that the term altered should be changed in a more specific way. 


\section{Table 2. Items Content Validity (I-CVI) of Two Nursing Diagnoses (Constipation, Diarrhea)}

\begin{tabular}{|c|c|c|c|}
\hline Nursing diagnosis & Item & $\begin{array}{l}\text { Number of ratings } \\
\text { of } 3 \text { or } 4\end{array}$ & CVI (item) \\
\hline \multirow[t]{4}{*}{ Constipation $^{a}$} & Frequency of bowel evacuations (weekly): $<2$ TIMES & 11 & 1.00 \\
\hline & $\begin{array}{l}\text { Reduced frequency of bowel evacuation over the last } 3 \\
\text { months: YES }\end{array}$ & 10 & 0.91 \\
\hline & Consistency of stool: HARD & 11 & 1.00 \\
\hline & Difficulty during defecation: YES & 11 & 1.00 \\
\hline \multirow[t]{2}{*}{ Diarrhea $^{a}$} & Consistency of stool: LIQUID/SEMI-LIQUID & 11 & 1.00 \\
\hline & Frequency of bowel evacuations (daily) > 3: YES & 10 & 0.91 \\
\hline
\end{tabular}

aNursing Diagnoses-Definitions and Classification 2012-2014. Copyright (c) 2012, 1994-2012 by NANDA-I. Used by arrangement with John Wiley \& Sons Limited. In order to make safe and effective judgments using NANDA-I nursing diagnoses, it is essential that nurses refer to the definitions and defining characteristics of the diagnoses listed in this work.

Therefore, the items were reformulated on the basis of the experts' comments. Based on the general comments of the experts, one diagnosis needed the addition of two items and another diagnosis needed the addition of one item. Finally, another diagnosis had an item that did not reach an adequate CVI.

\section{NAF Content Validity Delphi Phase 2}

The construction of the second questionnaire was based on experts' evaluations about the first phase.

The items related to mental status were reformulated, removing the terms identified as too general and unspecific, and replacing them with statements believed to be clearer and more specific. Moreover, two items regarding the body mass index (BMI) were added to the diagnosis of "risk for impaired skin integrity"; one item concerning the intake of fiber in the diet was added for the diagnosis of "risk of constipation"; and finally, for the diagnosis "deficient fluid volume," after discussion with the research team, an item that did not achieve an appropriate CVI was removed. The added items regarding the BMI and the intake of fiber in the diet were derived from the lists included in NANDA-I (Herdman, 2012). The expert ratings on the second questionnaire showed an excellent I-CVI, with an agreement of above $80 \%$ for all items. The D-CVI/Ave for the nine reformulated diagnoses was equal to or greater than $90 \%$.

\section{General Comments of the Experts}

Several experts' comments pointed out that for certain diagnoses, some objective scales should be added to support the assessment. The research team discussed this issue and came to the conclusion of adding four scales (with reliability and validity already established) related to four diagnoses. These scales are linked to specific diagnoses representing critical aspects of nursing care (falls, independence, pressure ulcer risk, and swallow). They are widely used in assessing Italian patients, and by law from the National Health Service for long-term care settings, some of them (e.g., the Barthel index) are required.

\section{Discussion}

Content validity is a crucial factor in the selection or application of an instrument. It involves the agreement by a specific number of experts that the items and entire instrument represent a specific diagnostic concept. During each phase, the expert panel identified areas that were unclear and suggested modifications and improvements, while the research team calculated the content relevance of each item and diagnosis. Expert consensus was achieved on the validated instrument to support nurses in the identification of one or more nursing diagnoses based on the nursing assessment.

The major defining characteristics and risk factors of each nursing diagnosis were taken as a starting point in the spotting of suitable items that would trigger the identification of one or more nursing diagnosis using the NAF.

The experts agreed that 37 of the 44 diagnoses were correctly represented by the items included in the NAF. The expert panel and the research group debated more widely about some specific items, the ones related to the mental status assessment. In this case, it was necessary to reformulate these items to avoid the misidentification of the related diagnosis. In nursing and medical notes, the assessment of mental status is often difficult and is under-recognized (Naylor et al., 2007). Several experts emphasized the use of specific assessment scales for a more objective and focused nursing assessment to reduce the subjective interpretation of data. Indeed, the nature of nursing data is potentially open to subjective interpretation as they are based on the identification of human answers and experience rather than diagnostic tests or biological parameters (Lunney, 2010). Assessment tools with positive estimates of validity, as achieved in this study, will bring more rigor to the process of nursing diagnosis identification and the realization of the NAF as a first step in this direction.

This study has some limitations. First, a small panel of experts provided judgment on content validity of the NAF. Furthermore, our sample of experts consisted of participants from several health settings but none from long-term or community healthcare settings. 
Table 3. Diagnoses Content Validity (D-CVI/Ave)

\begin{tabular}{|c|c|}
\hline Nursing diagnosis & D-CVI/Ave \\
\hline Imbalanced nutrition: less than body requirements ${ }^{a}$ & 0.97 \\
\hline Imbalanced nutrition: more than body requirements ${ }^{a}$ & 0.95 \\
\hline Deficient fluid volume ${ }^{a}$ & 0.79 \\
\hline Impaired swallowing a & 1.00 \\
\hline Constipation $^{\mathrm{a}}$ & 0.98 \\
\hline Perceived constipation ${ }^{a}$ & 0.91 \\
\hline Diarrhea $^{a}$ & 0.95 \\
\hline Bowel incontinence ${ }^{a}$ & 1.00 \\
\hline Impaired urinary elimination ${ }^{a}$ & 1.00 \\
\hline Functional urinary incontinence ${ }^{a}$ & 1.00 \\
\hline Stress urinary incontinence ${ }^{a}$ & 1.00 \\
\hline Urge urinary incontinence ${ }^{a}$ & 1.00 \\
\hline Reflex urinary incontinence ${ }^{a}$ & 1.00 \\
\hline Ineffective peripheral tissue perfusion ${ }^{a}$ & 0.91 \\
\hline Impaired physical mobility ${ }^{a}$ & 1.00 \\
\hline Sleep pattern disturbance ${ }^{a}$ & 0.91 \\
\hline Feeding self-care deficit ${ }^{a}$ & 0.96 \\
\hline Bathing self-care deficit ${ }^{a}$ & 1.00 \\
\hline Toileting self-care deficit ${ }^{a}$ & 1.00 \\
\hline Dressing self-care deficit ${ }^{a}$ & 1.00 \\
\hline Impaired skin integrity ${ }^{a}$ & 0.91 \\
\hline Ineffective airway clearance ${ }^{a}$ & 1.00 \\
\hline Impaired memory & 0.73 \\
\hline Impaired social interaction ${ }^{a}$ & 1.00 \\
\hline Chronic confusion $^{a}$ & 0.82 \\
\hline Acute confusion ${ }^{\mathrm{a}}$ & 0.88 \\
\hline Anxiety ${ }^{a}$ & 0.90 \\
\hline Fear $^{\mathrm{a}}$ & 0.95 \\
\hline Activity intolerance ${ }^{a}$ & 0.97 \\
\hline Acute pain ${ }^{a}$ & 1.00 \\
\hline Chronic pain ${ }^{a}$ & 1.00 \\
\hline Disturbed body image $^{a}$ & 1.00 \\
\hline Ineffective breathing pattern ${ }^{a}$ & 1.00 \\
\hline Fatigue $^{a}$ & 1.00 \\
\hline Impaired walkinga & 0.91 \\
\hline Ineffective coping ${ }^{a}$ & 0.94 \\
\hline Noncompliance ${ }^{a}$ & 1.00 \\
\hline Risk for injury ${ }^{a}$ & 0.86 \\
\hline Risk for falls ${ }^{a}$ & 0.84 \\
\hline Risk for aspiration ${ }^{a}$ & 0.93 \\
\hline Risk for constipation ${ }^{a}$ & 0.84 \\
\hline Risk for infection ${ }^{a}$ & 0.90 \\
\hline Risk for impaired skin integrity ${ }^{a}$ & 0.97 \\
\hline Risk for activity intolerance ${ }^{a}$ & 0.91 \\
\hline
\end{tabular}

${ }^{a}$ Nursing Diagnoses-Definitions and Classification 2012-2014. Copyright ( $)$ 2012, 1994-2012 by NANDA-I. Used by arrangement with John Wiley \&

Sons Limited. In order to make safe and effective judgments using NANDA-I nursing diagnoses it is essential that nurses refer to the definitions and defining characteristics of the diagnoses listed in this work.

The strengths of the method used in this validation process are that multiple methods were used to assure the process of selecting items, including the use of the current literature and a content validation performed by a panel of experts. Although the validity of the NAF was estimated in this study using a panel of experts, further validity and reliability testing in clinical practice is recommended. Other information that could enhance the quality of collected data can be entered as free text in the NAF. Over time, the free text can be examined for additional descriptors associated with specific NANDA-I diagnoses. Future plans for research involve the introduction of further specific scales to be linked to additional nursing diagnosis in order to provide more objective evidence to the identified nursing diagnosis.

Thanks to the fact that items included within the NAF act as a trigger for some diagnoses, the use of that nursing assessment form can help the nurse in diagnostic reasoning, thus facilitating the identification of the more suitable nursing diagnosis, and become the foundation for identification of appropriate nursing interventions and clientspecific outcomes. As argued by Choi, Choi, Bae, and Lee (2011), nurses repeatedly stated that clinical decision support systems can lead to improved patient outcomes through the application of standardized nursing care.

\section{Conclusions}

The assessment of client problems, as for other assessment methods, is a dynamic rather than static construct. A digital instrument could be useful for healthcare professionals in their effort to manage the ever-growing amount of clinical data. The use of an instrument that supports nurses in the identification of nursing diagnoses obviously does not replace the specific skills needed to perform adequate diagnostic reasoning. The nurse, as Gordon (1994) states, remains the most sensitive measurement tool. Critical thinking abilities will improve with appropriate thinking strategies that should be implemented through training and professional involvement (Lunney, 2010; Tanner, 2006). However, the implementation of standard instruments for nursing assessment can help nurses in the diagnostic reasoning and in the use of standardized terminology. Finally, the development of a valid and reliable instrument occurs over time, with repeated use and continuous improvements of the instrument itself. The computerization of data provides great opportunities for the nursing profession. Once the nursing information systems are developed, it is expected that the use of reliable and valid instruments will promote the quality of collected data and support nursing care to achieve improved outcomes of care.

Under the current demographic trends and the consequent epidemiological transition, an instrument facilitating the implementation of a professional standardized language will provide the content for healthcare information flow that goes far beyond only the clinical considerations, providing opportunities for discussion and research.

The electronic availability of accurate nursing diagnoses will accelerate nursing research and the development of nursing knowledge. With standardized electronic data, nurse researchers could compare data collected across several healthcare settings evaluating the contribution of nursing care in patient outcomes, thus enabling new models of data-driven care.

Future research should test the use of the NAF in clinical practice and measure its impact on nurse decision making as they formulate nursing diagnoses. In particular, it will be important to prospectively evaluate the degree of agreement between the nursing diagnoses suggested by the NAF 
and the actual diagnoses chosen by nurses. This kind of evaluation will produce evidence about the effectiveness of the NAF in providing decision support at the point of care. Further studies can also evaluate NAF accuracy and efficiency to formulate a diagnosis, as well as time required for diagnosis, and the perception of nurses about the use of NAF.

Acknowledgment. The authors thank the Center of Excellence for Nursing Scholarship IPASVI of Rome for funding the study.

\section{References}

Agency for Public Health, Lazio Region. Directive No. 6, December 28, 2010. Extension of the hospital discharge form (Ampliamento della Scheda di Dimissione Ospedaliera per la rilevazione di informazioni sulla Continuità Assistenziale). (July 4, 2012). Retrieved from http://www.asplazio.it/ asp_online/att_ospedaliera/files/files_sio/rad_sica/

DIR_6_28_12_2010_Ampliamento_scheda_RAD_SICA.zip

American Nurses Association. (2010). Nursing-standards of practice. (January 17, 2012). Retrieved from http://www.nursingworld.org/ MainMenuCategories/ThePracticeofProfessionalNursing/ NursingStandards/3-S-Booklet.pdf

Bergh, A. L., Bergh, C. H., \& Friberg, F. (2007). How do nurses record pedagogical activities? Nurses' documentation in patient records in a cardiac rehabilitation unit for patients who have undergone coronary artery bypass surgery. Journal of Clinical Nursing, 16(10), 1898-1907.

Bernhart-Just, A., Lassen, B., \& Schwendimann, R. (2010). Representing the nursing process with nursing terminologies in electronic medical record systems: A Swiss approach. Computers, Informatics, Nursing: CIN, 28(6), 345-352.

Carpenito-Moyet, L. J. (2008). Nursing diagnosis: Application to clinical practice (12th ed.). Philadelphia: Lippincott Williams \& Wilkins.

Choi, M., Choi, R., Bae, Y. R., \& Lee, S. M. (2011). Clinical decision support systems for patient safety: A focus group needs assessment with Korean ICU nurses. Computers, Informatics, Nursing: CIN, 29(11), 671-678.

D'Agostino, F., Vellone, E., Tontini, F., Zega, M., \& Alvaro, R. (2012). Sviluppo di un sistema informativo utilizzando un linguaggio infermieristico standard per la realizzazione di un Nursing Minimum Data Set [Development of a computerized system using standard nursing language for creation of a Nursing Minimum Data Set]. Professioni Infermieristiche, 65(2), 103109.

De Marinis, M. G., Piredda, M., Pascarella, M. C., Vincenzi, B., Spiga, F., Tartaglini, D., ... Matarese, M. (2010). "If it is not recorded, it has not been done!"? Consistency between nursing records and observed nursing care in an Italian hospital. Journal of Clinical Nursing, 19(11-12), 1544-1552.

Gordon, M. (1994). Nursing diagnosis: Process and application (3rd ed.). St. Louis, MO: Mosby.

Gordon, M. (2008). Manuale delle diagnosi infermieristiche [Manual of nursing diagnosis] (2nd ed.). Naples, Italy: EdiSES.

Hasson, F., Keeney, S., \& McKenna, H. (2000). Research guidelines for the Delphi survey technique. Journal of Advanced Nursing, 32(4), 1008-1015.

Häyrinen, K., Lammintakanen, J., \& Saranto, K. (2010). Evaluation of electronic nursing documentation-Nursing process model and standardized terminologies as keys to visible and transparent nursing. International Journal of Medical Informatics, 79, 554-564.

Herdman, T. H. (Ed.) (2012). NANDA International nursing diagnoses: Definitions and classification, 2012-2014. Oxford: Wiley-Blackwell.

Higuchi, K. A., Dulberg, C., \& Duff, V. (1999). Factors associated with nursing diagnosis utilization in Canada. Nursing Diagnosis, 10(4), 137-147.
Johnson, M., Bulechek, G., McCloskey Dochterman, J., Maas, M., \& Moorhead, S. (2001). Nursing diagnosis, outcomes and interventions: NANDA, NOC and NIC linkages. St. Louis, MO: Mosby.

Kurashima, S., Kobayashi, K., Toyabe, S., \& Akazawa, K. (2008). Accuracy and efficiency of computer-aided nursing diagnosis. International Journal of Nursing Terminologies and Classifications, 19(3), 95-101.

Law Decree No. 251. August 10, 2000. Regulation of the health care professions (Disciplina delle professioni sanitarie infermieristiche, tecniche, della riabilitazione, della prevenzione nonché della professione ostetrica). (July 4, 2012). Retrieved from http://www.camera.it/parlam/ leggi/002511.htm

Lemay, C. A., Cashman, S. B., Savageau, J. A., \& Reidy, P. A. (2004). Effect of a low-cost intervention on recording body mass index in patients' records. Journal of Nursing Scholarship, 36(4), 312-315.

Lunney, M. (2010). II pensiero critico nell'assistenza infermieristica: Casi clinici con Nanda-I, NOC e NIC [Critical thinking to achieve positive health outcomes: nursing case studies and analyses]. Milan, Italy: Casa Editrice Ambrosiana.

Lynn, M. R. (1986). Determination and quantification of content validity. Nursing Research, 35(6), 382-385.

Ministerial Decree No. 739. September 14, 1994. Nurse professional profile (Regolamento concernente l'individuazione della figura e del relativo profilo professionale dell'infermiere). (July 4, 2012). Retrieved from http://www.ipasvi.it/archivio_news/leggi/179/DM140994n739.pdf

Müller-Staub, M., Lavin, M. A., Needham, I., \& van Achterberg, T. (2006). Nursing diagnoses, interventions and outcomes-application and impact on nursing practice: Systematic review. Journal of Advanced Nursing, 56(5), 514-531.

Müller-Staub, M., Needham, I., Odenbreit, M., Lavin, M. A., \& van Achterberg, T. (2007). Improved quality of nursing documentation: Results of a nursing diagnoses, interventions, and outcomes implementation study. International Journal of Nursing Terminologies and Classifications, 18(1), 5-17.

Müller-Staub, M., Needham, I., Odenbreit, M., Lavin, M. A., \& van Achterberg, T. (2008). Implementing nursing diagnostics effectively: Cluster randomized trial. Journal of Advanced Nursing, 63(3), 291-301.

Naylor, M. D., Hirschman, K. B., Bowles, K. H., Bixby, M. B., Konick-McMahan, J., \& Stephens, C. (2007). Care coordination for cognitively impaired older adults and their caregivers. Home Health Care Services Quarterly, 26(4), 57-78.

Paans, W., Nieweg, R. M., van der Schans, C. P., \& Sermeus, W. (2011). What factors influence the prevalence and accuracy of nursing diagnoses documentation in clinical practice? A systematic literature review. Journal of Clinical Nursing, 20(17-18), 2386-2403.

Paans, W., Sermeus, W., Nieweg, R. M., \& van der Schans, C. P. (2010). Prevalence of accurate nursing documentation in patient records. Journal of Advanced Nursing, 66(11), 2481-2489.

Paganin, A., Moraes, M. A., Pokorski, S., \& Rabelo, E. R. (2008). Factors that inhibit the use of nursing language. International Journal of Nursing Terminologies and Classifications, 19(4), 150-157.

Peres, H. H., de Almeida Lopes Monteiro da Cruz, D., Lima, A. F., Gaidzinski, R. R., Ortiz, D. C., Mendes e Trindade, M., ... Batista de Oliveira, N. (2010). Conceptualization of an electronic system for documentation of nursing diagnosis, outcomes, and intervention. Studies in Health Technology and Informatics, 160, 279-283.

Tanner, C. A. (2006). Thinking like a nurse: A research-based model of clinical judgment in nursing. Journal of Nursing Education, 45(6), 204-211.

Thoroddsen, A., \& Ehnfors, M. (2007). Putting policy into practice: Pre-and posttests of implementing standardized languages for nursing documentation. Journal of Clinical Nursing, 16(10), 1826-1838.

Welton, J. M., \& Halloran, E. J. (2005). Nursing diagnoses, diagnosis-related group, and hospital outcomes. Journal of Nursing Administration, 35(12), 541-549.

Yeh, S. H., Jeng, B., Lin, L. W., Ho, T. H., Hsiao, C. Y., Lee, L. N., \& Chen, S. L. (2009). Implementation and evaluation of a nursing process support system for long-term care: A Taiwanese study. Journal of Clinical Nursing, 18(22), 3089-3097. 